\title{
GAO Algoritma tabanlı YSA modeliyle İHA motorunun performansının ve uçuş süresinin maksimizasyonu
}

\author{
Mehmet Konar ${ }^{1 *}$ \\ ${ }^{1}$ Erciyes Üniversitesi, Havacılık ve Uzay Bilimleri Fakültesi, Uçak Elektrik-Elektronik Bölümü, Kayseri, Türkiye (ORCID: 0000-0002-9317-1196)
}

(İlk Geliş Tarihi 19 Şubat 2019 ve Kabul Tarihi 6 Mart 2019)

(DOI: 10.31590/ejosat.529093)

\begin{abstract}
ATIF/REFERENCE: Konar, M. (2019). GAO Algoritma tabanlı YSA modeliyle İHA motorunun performansının ve uçuş süresinin maksimizasyonu. European Journal of Science and Technology, (15), 360-367.
\end{abstract}

\begin{abstract}
Öz
İnsansız hava araçları (IHHA), istenen görevleri yerine getirebilme kabiliyetine sahip olarak tasarlanmış hava araçlarıdır. Bu hava araçlarının tasarımında, motor performansı ve uçuş süresinin maksimizasyonu büyük önem arz etmektedir. Bu çalışmada, İHA'nın fırçasız motorunun performansının ve uçuş süresinin maksimizasyonu ele alınmıştır. Bu amaçla, Geri-İzleme Arama Optimizasyon (GAO) algoritması tabanlı Yapay Sinir Ağlarına (YSA) dayanan bir model önerilmiştir. Önerilen modelde, firçasız motor hızını ayarlayan elektronik hız kontrol (EHK) ünitesi sinyali, firçasız motorun dakikadaki dönüş sayısı (DDS), pervanenin çapı ve hatvesi giriş parametreleri olarak belirlenmiş; gerekli itki kuvveti, uçuş süresi ve motor verimliliği çıkış parametreleri olarak belirlenmiştir. Böylece, 4 giriş 3 çıkışa sahip bir model oluşturulmuştur. Önerilen modelin eğitim işleminde kullanmak için, firçasız motordan RCbenchmark firmasının 1580 modeli dinamometresi yardımıyla, farklı değer aralıklarında veriler üretilmiştir. Üretilen bu veriler kullanılarak optimum YSA yapısına ait parametreler GAO algoritması ile belirlenmiştir. Optimum olarak belirlenen bu YSA yapısı amaç fonksiyonunu gerçekleştirmek üzere GAO algoritması ile entegre edilmiştir. Bu entegrasyonla birlikte GAO algoritmasına dayanan model ile maksimum motor performansı ve uçuş süresi için giriş parametre değerlerinin elde edilmesi sağlanmıştır. Yani, GAO algoritması hem YSA yapısının optimizasyonu hem de firçasız motor performansı ve uçuş süresinin maksimizasyonu için gerekli parametrelerin elde edilmesi için kullanılmıştır. Çalışma sonucunda elde edilen sonuçlar tablolar ve şekiller vasıtasıyla sunulmuştur. GAO algoritması tabanlı YSA modeli ile yapılan simülasyon çalışmalarında elde edilen sonuçlar, önerilen yöntemin İHA tasarımcıları için kolaylık sağlayacağını göstermiştir.
\end{abstract}

Anahtar Kelimeler: İHA, Geri-izleme arama optimizasyon algoritması, Uçuş süresi, Optimizasyon, Yapay sinir ağları.

\section{The Maximization of the UAV Engine Performance and Flight Time by BSA based ANN model}

\begin{abstract}
Unmanned aerial vehicles (UAVs) are aircraft that designed to carry out the desired tasks. In the design of these aircraft, the maximization of engine performance and flight time is very important. In this study, the maximization of the UAV's brushless motor performance and flight time are discussed. For this purpose, a model based on Artificial Neural Networks (ANN) depending on BackTracking Search Optimization (BSO) algorithm is proposed. In the proposed model, four parameters including the signal of electronic speed control (ESC) unit that adjusts the brushless engine speed, the number of rotations of the brushless motor (RPM) per minute, the propeller size, and the propeller pitch were selected as input parameters. The required thrust, flight time and engine efficiency were selected as output parameters. Thus, a model with 4 inputs and 3 outputs was formed. To use the in the training process of the proposed model, data was obtained from the brushless motor with the help of RCBenchmark's 1580 model dynamometer. By using these produced data, the parameters of the optimum ANN structure were determined by BSO algorithm. The ANN structure that
\end{abstract}

* Corresponding Author: Erciyes Üniversitesi, Havacıllk ve Uzay Bilimleri Fakültesi, Uçak Elektrik-Elektronik Bölümü, Kayseri, Türkiye, ORCID: 0000-0002-9317-1196, mkonar@erciyes.edu.tr 
optimally determined was integrated with the BSO algorithm to achieve the objective function. With this integration, the model based on the BSO algorithm provided the values of input parameters for maximum engine performance and maximum flight time. That is, the BSO algorithm was used both to optimize the ANN structure and to obtain the parameters required for maximization of brushless engine performance and flight time. The results of the study were presented by tables and figures. The results obtained in the simulation process with the BSO Algorithm based ANN model showed that the proposed method will be facilitated the UAV design for designers.

Keywords: UAV, Backtracking search optimization algorithm, Flight time, Optimization, Artificial neural networks.

\section{Giriş}

İnsansız hava araçları (İHA), sahip olduğu teknolojik yetenekleriyle hem askeri hem de sivil alanlardaki uygulamaların gerekliliklerini karşılamaktadır. İHA teknolojilerine, havacılık, robotik, elektronik donanım, yazılım ve uygulama enstrümantasyonu gibi birçok alan katkı sağlamaktadır. Kullanılan teknolojik alt yapıyla birlikte, İHA sistemleri günümüzde sıradan bir yapıya sahip gibi görünsede, güvenlik protokolleri ve operatör gereksinimleri geliştirilmiştir. Geliştirilen operatör desteklerine göre yarı otonom ya da tam otonom olarak İHA'lar görevlerini gerçekleştirebilmektedir [1].

Görev gereksinimlerine göre İHA’lar farklı boyutlarda tasarlanmıştır. Mini boyuttan, insanlı uçakların boyutlarına kadar çeşitli İHA'lar bulunmaktadır. Büyük boyutlu İHA'lar geleneksel insanlı uçaklarla benzer altyapıları kullanan sabit kanatlı hava araçlarıdır. Küçük boyutlu İHA'ların ise sabit ve döner kanatlı gibi farklı türleri bulunmaktadır [2].

Küçük İHA'lar genellikle birçok tasarımcı tarafından yüksek oranda yapılandırılabilmektedir. Kamera sistemleri gibi çeşitli yük kombinasyonları ile entegre edilebilmektedir. Aynı zamanda çeşitli pil, motor ve pervane konfigürasyonları gerçekleştirilebilmektedir. Belirli bir konfigürasyonun performansının yeterli olduğunu doğrulamak için doğrudan deneysel test yapılması gerekmektedir. Fakat test sürelerinin vakit alıcı olması, tasarım sürelerini arttırmaktadır. Bu gibi nedenlerle, birçok tasarımcı farklı yöntemlere başvurmaktadır. Tasarım sürecinde başvurulan yöntemlerden biride sezgisel algoritmaların kullanılmasıdır. Sezgisel algoritmalar, sınırlı sayıda üretilen veriler ile istenen en iyi çözümün elde edilmesinde tasarımcılara büyük katkı sağlamaktadır [3-5].

Bir yaklaşımda en iyilemeyi ifade eden optimizasyon, problem çözümlerine yardımcı olmaktadır. Farklı problemlerin çözümünde, belirli şartlar dahilinde, minimum ve maksimum değerleri veren parametre değerlerinin, en uygun şekilde belirlenmesinde farklı bir çok sezgisel algoritmadan yararlanılmıştır. Aerodinamik tasarım, itki sistemi tasarımı, havada kalış süresinin ve menzilin arttırılması, otonom sistem tasarımı gibi birçok çalışmada sezgisel algoritmalar kullanılmıştır [3-12]. Batarya ile çalışan İHA'ların menzilinin arttırılması üzerine çalışma Traub [6] tarafından yapılmıştır. İHA'ların optimum tahrik sistemi üzerine tasarım Gur ve Rosen [7] tarafından yapılmıştır. Uzun menzilli İHA’nın analizi üzerine çalışmalar ise Lawrance ve Mohseni [8] tarafından yapılmıştır.

$\mathrm{Bu}$ çalışmada İHA’nın firçasız motor performansının ve uçuş süresinin maksimizasyonunun eş zamanlı hesaplanması amaçlanmaktadır. Hesaplama için Yapay Sinir Ağları (YSA) ile entegre edilmiş Geri-İzleme Arama Optimizasyon (GAO) algoritmasına dayanan bir yöntem sunulmuştur. İki aşamadan oluşan bu yöntemin ilk aşamasında dinamometreden elde edilen veriler kullanılarak, en uygun YSA modelinin parametreleri GAO algoritmasıyla belirlenmiştir. Daha sonra, elde edilen optimum YSA yapısı amaç fonksiyonunu gerçekleştirmek amacıyla GAO algoritmasına entegre edilmiştir. Böylece, GAO algoritması kullanılarak maksimum firçasız motor performansının ve uçuş süresinin eş zamanlı ve eşit önemde dikkate alınmasıyla optimum giriş değerleri hesaplanmıştır.

Çalışmanın ikinci bölümünde GAO algoritması açıklanmıştır [13,14]. Üçüncü bölümde YSA'nın eğitim işleminde kullanılan verilerin deneysel olarak elde edilmesinden bahsedilmiştir. Dördüncü bölümde problem formülüzasyonu ve YSA açıklanmıştır [1517]. Ayrıca, YSA parametrelerinin ayarlanması ve GAO algoritmasıyla yapılan maksimizasyon işlemi de bu bölümde açıklanmıştır. Beşinci bölümde, yapılan çalışmada elde edilen sonuçlar tablo ve şekillerle sunulmuştur. Son bölümde ise sonuçlara yer verilmiştir.

\section{GAO Algoritması}

GAO algoritması, süre tabanlı bijektif bir evrimsel algoritmadır. GAO algoritması, optimizasyon problemlerindeki lokal çözümlerden kaçınarak global çözümlerin elde edilmesini sağlamaktadır. Algoritmanın çalışması; ilk değerlerin verilmesi, birinci seçim aşaması, mutasyon, çaprazlama ve ikinci seçim aşaması olmak üzere 5 temel aşama üzerine kurulmuştur [13].

İlk değerin verilmesi aşaması, Eşitlik 1 ile tanımlanmaktadır. Burada, $P$ popülasyon büyüklüğ̈̈, $D$ problemin boyutu, $P_{i, j}$ popülasyon içerisindeki bir hedef bireyi, $l o w_{j}$ ve $u p_{j}$ ise sırasıyla çözüm uzayındaki en alt ve en üst sınır değerlerini ifade etmektedir.

$$
P_{i, j} \sim U\left(\operatorname{low}_{j}, u p_{j}\right)
$$

Birinci seçim aşaması, arama yönünü hesaplamak için oldP tarihsel popülasyonunu belirler. Böylece, GAO algoritması geçmişte elde edilen değerleri, bir sonraki karar alma mekanizmasında kullanılmak üzere hafızaya alır. oldP'nin belirlenmesiyle birlikte popülasyon üyeleri rastgele olarak yeniden sıralanır.

Mutasyon (M) aşamasında, mutant popülasyonunun ilk değerleri hesaplanır (Eşitlik 2). Burada $F$ değeri, arama matrisinin genliğini ayarlamaktadır. Böylece, daha önceden elde edilen tecrübeler, arama yönünü belirlerken kullanılmış olmaktadır. 


$$
M=P+F(\text { old } P-P)
$$

Çaprazlama aşaması, değerlendirmeye alınacak popülasyonun son halini verir. Değerlendirmeye alınan popülasyon üyelerinden, optimizasyon problemine göre iyi değerlere sahip olanlar, hedef popülasyon bireylerini belirlemek için kullanılır.

GAO algoritması, mutasyona uğrayan popülasyon bireylerinin, çözüm uzayı sınırlarını aşmasını engellemek için sınırlandırma mekanizması da kullanmaktadır.

İkinci seçim aşaması, güncelleme işleminin yapıldığı ve iyi olanın seçildiği aşamadır. Küresel en iyi değer, her bir iterasyon çevriminde bütün popülasyon bireyleri ile karşılaştırılarak tekrar kontrol edilir. Eğer herhangi bir bireyin amaç fonksiyon değeri, mevcut küresel en iyi değerden daha iyi ise, bu durumda yeni küresel en iyi değer bu bireyin sahip olduğu konum olacaktır.

GAO algoritması, uygulama mantığının oldukça basit olmasından dolayı çeşitli mühendislik problemlerine kolayca uygulanabilmektedir $[13,14]$.

\section{Deneysel Çalışma}

Çalıșmanın bu bölümünde, İHA'larda kullanılan firçasız motorun performans analizi incelenmiștir. Yapılan çalıșmada RCbencmark firması tarafından üretilen 1580 modeli dinamometre ve bu dinamometreye ait arayüz yazılımı kullanılmıştır. Kullanılan yazılım ve dinamometre aracılığıyla İHA için tasarlanmış olan bir elektronik motorun performansı incelenmiştir. Çalışmada, Emax firmasına ait GT2215/09 model firçasız motorun itki, tork, pervane ve sistem verimliliği üzerine çeşitli testler yapılmıştır. Test esnasında fırçasız motorun hızını ayarlamak için 40 amper EHK ünitesi kullanılmıștır. Gerekli elektriksel enerji, Multistar 5200 mAH, $12 \mathrm{C}$ ve 11,1 volt özelliğine sahip Lityum polimer (Lipo) pilden sağlanmıştır.

Kullanılan programda EHK tetikleme aralığı 1000-2000 arasında belirlenmiştir. Yapılan deneysel çalışmada, üç farklı pervane için motora ait 25 farklı çalışma noktasında örnek alınmıștır. Her bir örnek olușturulurken, EHK örnek değerde, motor 3 sn boyunca çalıştırılmıştır. Bu çalışma süresince soğutulma yapılmamıştır. Motorun iki örnek değeri arasındaki geçiş süresi 10 sn olarak belirlenmiştir. Deneysel çalışmanın test düzeneği Şekil 1'de verilmiştir.

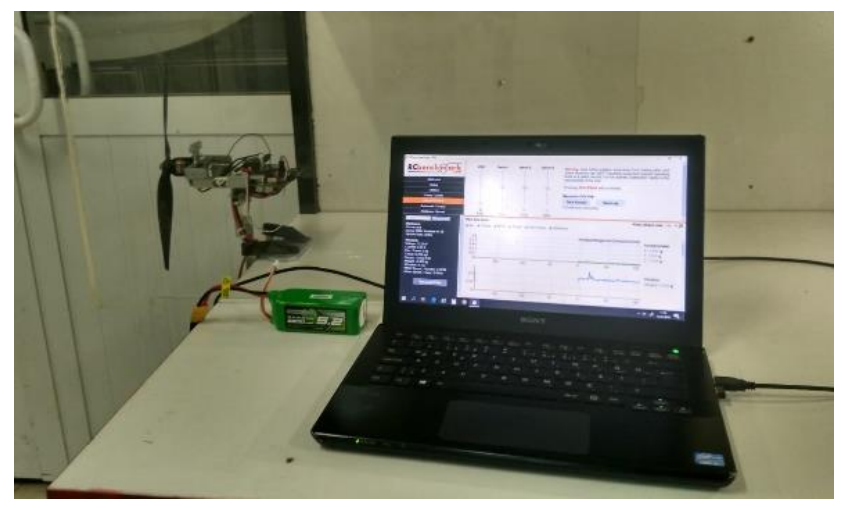

Şekil 1. Test düzeneği

Yapılan çalışmada farklı boyut ve hatvelere sahip pervanler kullanılmıştır. Kullanılan pervane boyutları sırasıyla 10x4.7, 10x5 ve 11x4.7'dir. Farklı pervaneler kullanıldığında motor aynı örnek değerlerinde çalıştırılmıştır. $\mathrm{Bu}$ da, pervanelerin performansının karşılaştırılmasına olanak sağlamıştır.

Deney sonucunda elde edilen değerler şekiller vasıtasıyla sunulmuştur. Şekil 2'de, üç farklı pervane için EHK ünitesi sinyaline karş1lık itki kuvvetinin değişimi verilmiştir. Şekilde görüldüğ̈̈ gibi, EHK sinyaliyle itki kuvveti doğru orantılı olarak artmıştır. Şekil 3'de, seçilen pervaneler için EHK sinyaline karşl1ık uçuş süresinin değişimi verilmiş̧tir. EHK sinyalinin artmasıyla birlikte, çekilen akım mikarı arttığı için uçuş süresinde azalma eğilimi gözlenmiştir. Şekil 4 ve Şekil 5 'te ise üç farklı pervane için sırasıyla EHK sinyaline karşılık motor verimliliğinin değişimi ve DDS'ye karşılık uçuş süresinin değişimi verilmiştir.

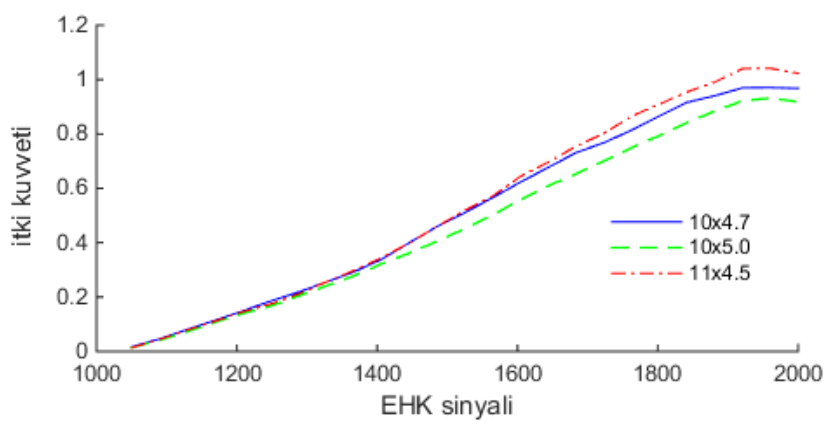

Şekil 2. EHK sinyaline karşllık itki kuvvetinin değişimi 


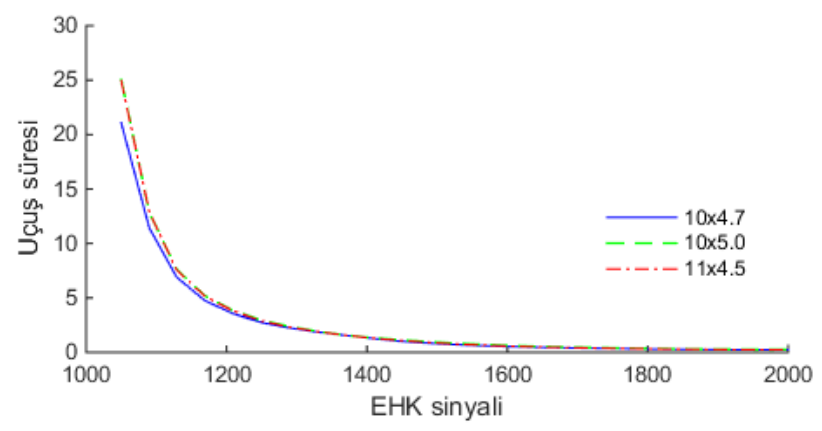

Şekil 3. EHK sinyaline karşılık uçuş süresinin değişimi

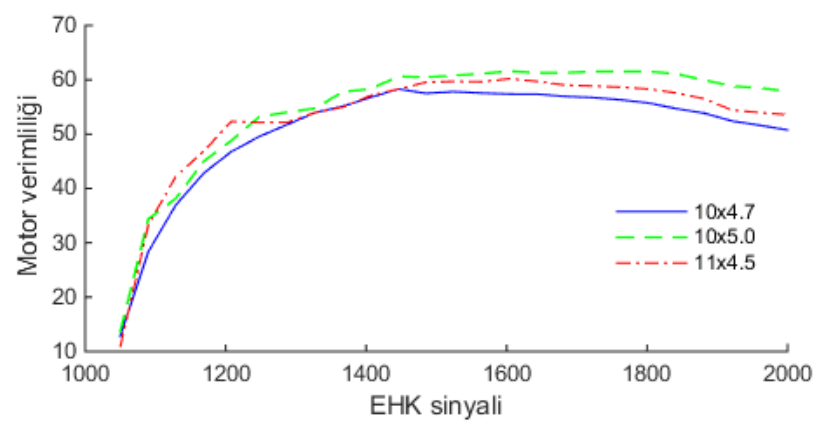

Şekil 4. EHK sinyaline karşılık motor verimliliğinin değişimi

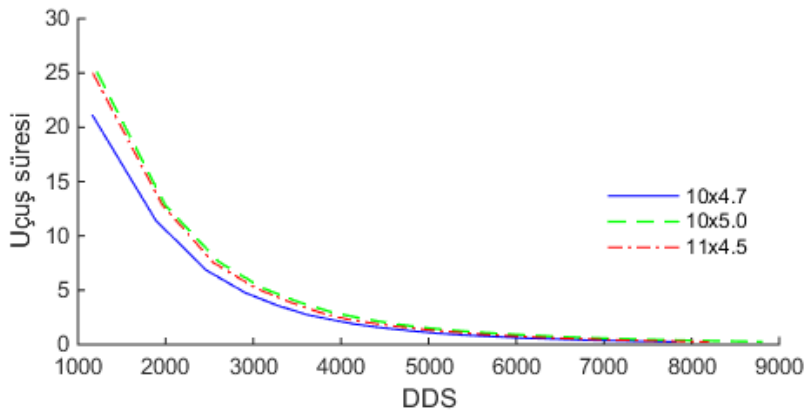

Şekil 5. DDS'ye karşılık uçuş süresinin değişimi

\section{Problem Formülüzasyonu ve Optimizasyon}

$\mathrm{Bu}$ çalışmada, İHA’nın firçasız motor performansının ve uçuş süresinin maksimizasyonu ele alınmıştır. Bu amaç için, GAO algoritması tabanlı YSA'ya dayanan bir model önerilmiştir. Önerilen modelin ilk aşamasını giriş ve çıkış parametrelerinin belirlenmesi oluşturmuştur.

Fırçasız motor hızını ayarlayan EHK ünitesi sinyali, fırçasız motorun dakikadaki dönüş sayısı, firçasız motorda kullanılan pervanenin çapı ve hatvesi giriş parametreleri olarak seçilmiştir. Model çıkışı olarak ise itki kuvveti, uçuş süresi ve motor verimliliği seçilmiştir. Böylece, 4 giriş 3 çıkışa sahip bir model yapısı oluşturulmuştur. Oluşturulan modelin performansını belirlemek için ortalama karesel hata $(\mathrm{OKH})$ kriteri kullanılmıştır $[18,19]$. Oluşturulan model yapısının blok diyagramı Şekil 6'da sunulmuştur. Çalışmada 75 adet veriden faydalanılmıştır.

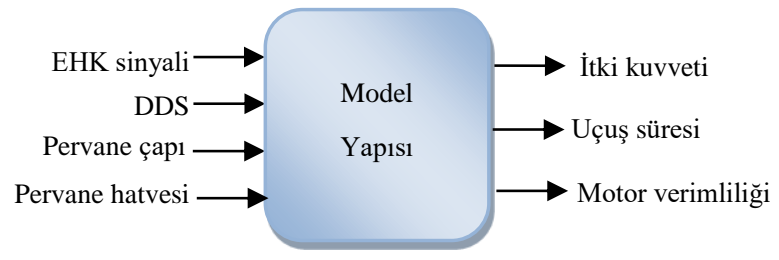

Şekil 6. Model Yapısı 


\section{Yapay Sinir A Ălart}

YSA'lar, örnekler yoluyla problemi öğrenebilen, edindiği bilgilere göre genelleme yaparak yeni bilgiler oluşturabilen, bilgi işleme sistemleridir [15].

YSA, giriş, ara ve çıkış olmak üzere üç katmandan oluşmaktadır. Giriş katmanı, uygulanan probleme ait eğitim örneklerinden oluşan veri kümesinden gelen bilgileri ara katmana iletmektedir. Ara katman, giriş katmanından gelen bilgiyi işleyip çıkış katmanına göndermektedir. Ara katman sayısı birden fazla olabilmektedir. Çıkış katmanı ise ara katmandan gelen bilgiyi işleyerek, ilgili girişe karşı üretilecek çıkışı hesaplamakta ve çıkış veri kümesinin oluşumunu sağlamaktadır [15-17]. YSA'nın temel yapısı Şekil 7'de verilmiş̧ir.

YSA hücre modellerinde kullanılan çeşitli tipte aktivasyon fonksiyonları bulunmaktadır. En uygun tanımlamanın yapılabilmesi için aktivasyon fonksiyonunun seçilmesi önemlidir. Lineer, basamak, eşik, hiperbolik tanjant gibi türleri olan aktivasyon fonksiyonunun en yaygın kullanılan tipi sigmoid fonksiyonlardır. YSA'nın eğitiminde, tanjant sigmoid (tansig), logaritmik sigmoid (logsig) ve lineer (purelin) aktivasyon fonksiyonları ara katman ve çıkış katmanları için literatürde sıklıkla tercih edilmektedir [3-4].

\section{Problem Formülüzasyon Aşaması}

Problemin çözümü, eğitim ve optimizasyon olmak üzere iki aşamada gerçekleştirilmektedir. Bu aşamaların blok diyagramı Şekil 8'de verilmiş̧ir. Eğitim aşamasında, seçilen parametrelerden oluşan veriler kullanılarak en uygun YSA modelinin elde edilmesi amaçlanmıştır. $\mathrm{Bu}$ aşamada, optimum YSA yapısının elde edilmesi için, YSA'nın ağılıkları GAO algoritması kullanılarak ayarlanmıştır. Bu amaçla, gerçek sistem çıkışı ile YSA model çıkışı arasında ki hata farkının minimizasyonu için, her çevrimde YSA yapısına ait ağırlık değerleri güncellenerek, optimum YSA modelinin elde edilmesi sağlanmıştır.

Eğitim aşamasında en uygun YSA model yapısının GAO algoritmasıyla belirlenmesinden sonra, çalışmanın bir sonraki aşaması başlatılmıştır. $\mathrm{Bu}$ aşamada, motor performansının ve uçuş süresinin daha iyi hale getirilmesi için optimizasyon işlemi gerçekleştirilmiştir. Bu amaçla, bir önceki aşamada elde edilen optimum YSA yapısı, maksimum çıkış değerlerinin elde edileceği amaç fonksiyonunu gerçekleştirmek için GAO algoritmasına entegre edilmiştir. Algoritma, üretilen hata değerini minimize edecek şekilde, çıkış parametre değerlerini maksimuma yaklaştırmayı sağlamıştır. Böylece, optimum çıkış parametrelerini veren optimum giriş parametreleri elde edilmiştir.

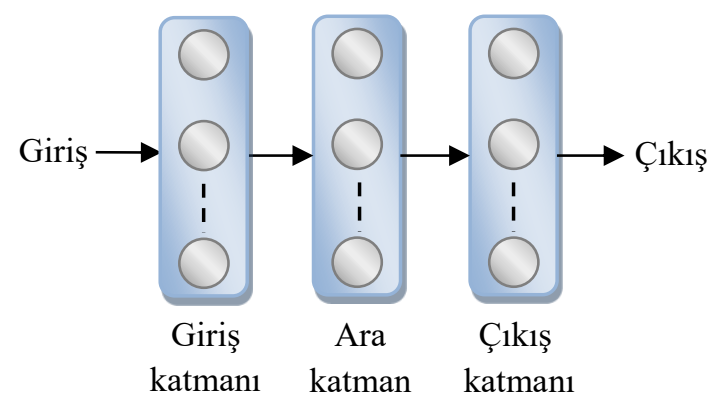

Şekil 7. YSA’nın temel yapısı

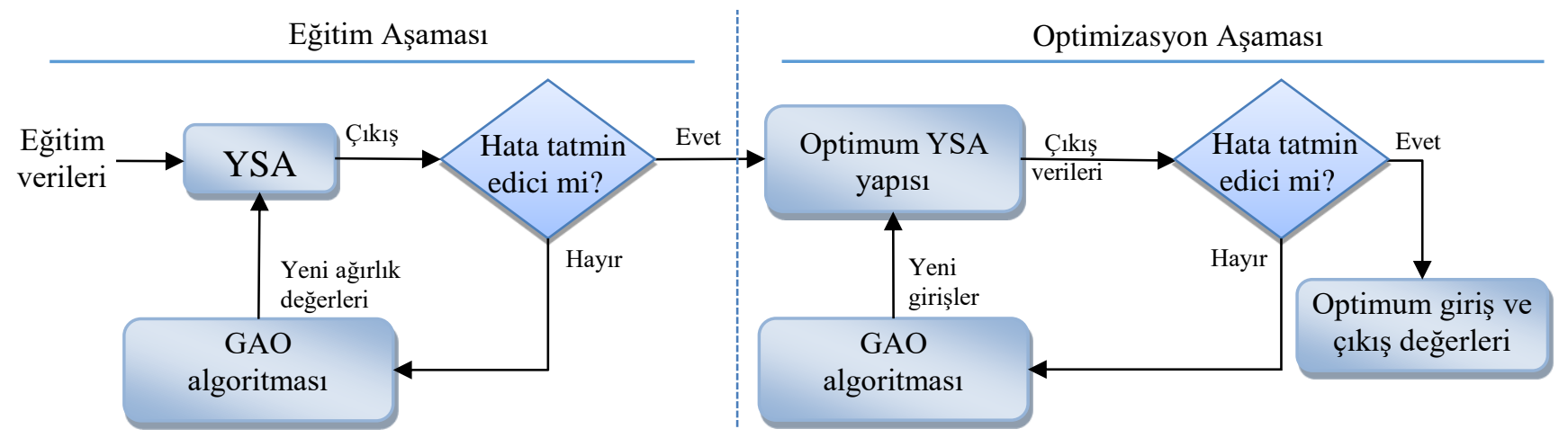

Şekil 8. Eğitim ve optimizasyon aşamalarının blok diyagramı

\section{Similasyon sonuçları}

YSA'nın eğitim aşamasında, ara ve çıkış katmanlarında kullanılan aktivasyon fonksiyonları sırasıyla logsig-logsig, tansig-purelin ve logsig-purelin şeklinde seçilmiştir.

GAO algoritmasının eğitim aşamasında kontrol parametreleri; koloni büyüklüğü 50, iterasyon sayısı sırasıyla 2500, 5000, 10000 ve runtime (tekrarlama sayısı) 30 olarak şeçilmiştir. Optimizasyon aşamasında ise optimum YSA yapısının kullanılmasıyla birlikte 
GAO algoritmasının kontrol parametreleri; 50 koloni, 250 iterasyon ve 1 runtime olarak belirlenmiştir. Seçilen bu parametreler ile eğitim ve optimizasyon işlemleri için elde edilen OKH değerleri Tablo 1'de sunulmuştur. Eğitim aşamasında 0.0011 ile en küçük OKH değerine sahip optimum YSA yapısı, logsig-logsig aktivasyon fonksiyonu ile elde edilmiştir. Aynı modelin optimizasyon aşamasında elde edilen OKH değeri 1.0172 olarak hesaplanmıştır. Elde edilen düşük OKH değerine sahip yapılar, İHA'nın en uygun motor performansı ve uçuş süresi maksimizasyonunun belirlenmesinde önerilen yöntemin güvenirliğini desteklemektedir.

En iyi performansa sahip YSA modelinin iterasyon sayısına karşılık OKH değişim grafiği Şekil 9'da gösterilmiştir. Aynı modelin optimizasyon aşamasındaki iterasyon sayısı-OKH değişim grafiği ise Şekil 10'da gösterilmiştir.

GAO algoritmasıyla yapılan simülasyonlar sonucunda elde edilen en iyi modele sahip İHA’ya ait EHK, DDS, pervanenin çapı, pervanenin hatvesi, itki kuvveti, uçuş süresi ve motor verimliliğinin parametre değerleri sırasıyla 10.9847, 4.8185, 2000, 8850, $0.9558,0.2029$ ve 57.0171 'dir.

Tablo 1. Eğitim ve optimizasyon işlemlerinde elde edilen $\mathrm{OKH}$ değerleri

\begin{tabular}{|c|c|c|c|c|c|c|c|c|c|}
\hline \multicolumn{5}{|c|}{ Eğgitim Aşaması } & \multicolumn{5}{|c|}{ Optimizasyon Aşaması } \\
\hline \multirow{2}{*}{ İterasyon } & \multirow{2}{*}{$\begin{array}{l}\text { Nöron } \\
\text { Sayısı }\end{array}$} & \multicolumn{3}{|c|}{ Aktivasyon Fonksiyonları } & \multirow{2}{*}{ İterasyon } & \multirow{2}{*}{$\begin{array}{l}\text { Nöron } \\
\text { Sayısı }\end{array}$} & \multicolumn{3}{|c|}{ Aktivasyon Fonksiyonları } \\
\hline & & Log-Log & Tan-Purelin & Log-Purelin & & & Log-Log & Tan-Purelin & Log-Purelin \\
\hline \multirow{5}{*}{2500} & 2 & 0.0042 & 0.0492 & 0.0100 & \multirow{15}{*}{250} & 2 & 1.0209 & 1.1138 & 1.0496 \\
\hline & 3 & 0.0037 & 0.0465 & 0.0110 & & 3 & 1.0082 & 0.4563 & 1.0734 \\
\hline & 4 & 0.0046 & 0.0554 & 0.0107 & & 4 & 1.0108 & 0.5032 & 0.5645 \\
\hline & 5 & 0.0039 & 0.0459 & 0.0184 & & 5 & 0.9980 & 0.9942 & 0.5032 \\
\hline & 10 & 0.0057 & 0.0514 & 0.0223 & & 10 & 0.3182 & 0.0828 & 0.0865 \\
\hline \multirow{5}{*}{5000} & 2 & 0.0026 & 0.0394 & 0.0032 & & 2 & 1.0037 & 0.2469 & 0.9301 \\
\hline & 3 & 0.0028 & 0.0414 & 0.0070 & & 3 & 1.0078 & 0.0385 & 0.7948 \\
\hline & 4 & 0.0025 & 0.0370 & 0.0029 & & 4 & 1.0136 & 0.1631 & 0.7471 \\
\hline & 5 & 0.0036 & 0.0309 & 0.0084 & & 5 & 0.0081 & 0.5748 & 0.3207 \\
\hline & 10 & 0.0039 & 0.0342 & 0.0121 & & 10 & 0.9851 & 0.0079 & 0.0098 \\
\hline \multirow{5}{*}{10000} & 2 & 0.0023 & 0.0130 & 0.0025 & & 2 & 1.0032 & 1.0337 & 0.6450 \\
\hline & 3 & 0.0013 & 0.0226 & 0.0032 & & 3 & 1.0163 & 0.8890 & 0.3792 \\
\hline & 4 & 0.0011 & 0.0205 & 0.0022 & & 4 & 1.0172 & 0.5491 & 0.6495 \\
\hline & 5 & 0.0017 & 0.0207 & 0.0025 & & 5 & 0.9735 & 0.1743 & 0.7762 \\
\hline & 10 & 0.0032 & 0.0208 & 0.0031 & & 10 & 0.8202 & 0.0333 & 0.6424 \\
\hline
\end{tabular}

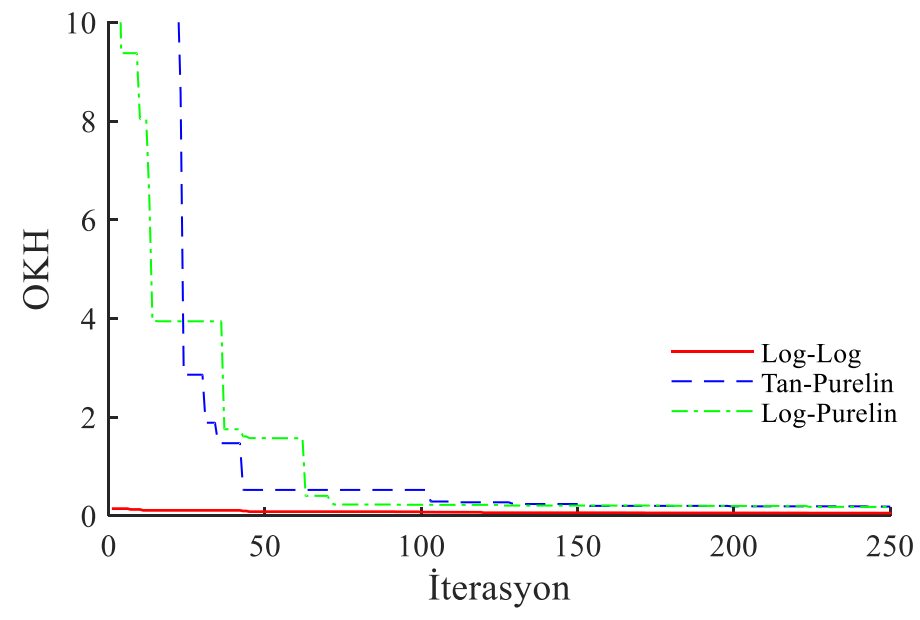

Şekil 9. Optimum YSA yapısı için iterasyon sayısı-OKH değişim grafiği (İlk 250 iterasyon) 


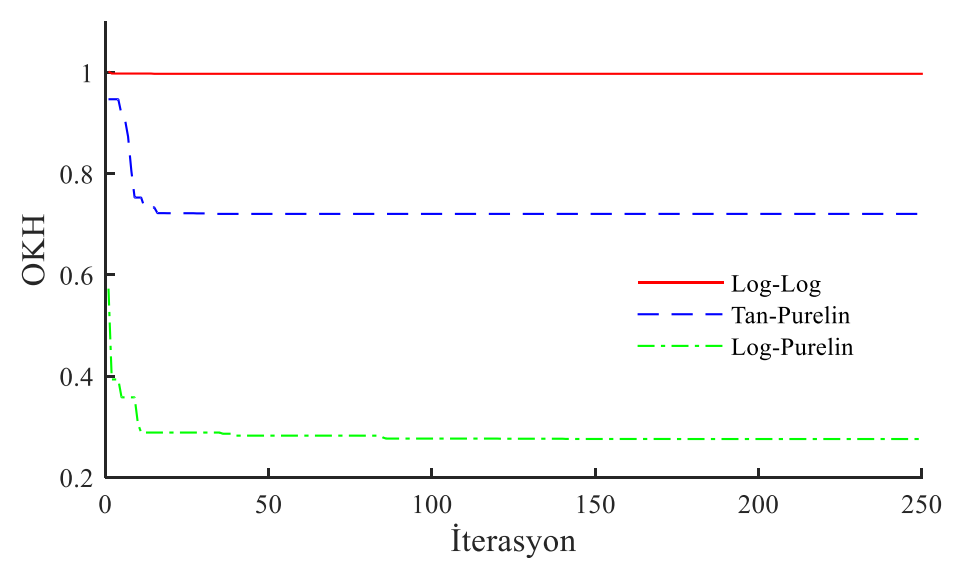

Şekil 10. Optimizasyon aşamasındaki iterasyon sayısı-OKH değişim grafiği

\section{Sonuçları}

İHA'lar, amatör ya da profesyonel olarak sivil, askeri ve ticari alanlarda kullanılmaktadırlar. Her kullanım alanının gereksinimine göre, kullanıcılar tarafından, farklı özelliklerde İHA'lar tercih edilmektedir. Farklı İHA'lar için yapılan tasarımların en iyi performansı sergilemesi beklenmektedir. İHA performansının geliştirilmesi için kullanılan klasik yöntemlere ek olarak, sezgisel yöntemlerin sağlayacağı katkıların da irdelenmesi önemli bir konudur. Bu nedenle, literatürde sezgisel algoritmaların İHA tasarımına katkısını konu alan pek çok çalışma mevcuttur.

$\mathrm{Bu}$ çalışmada ise, GAO algoritması tabanlı YSA modeline dayanan yöntemin, firçasız motorun performansındaki ve uçuş süresinin maksimizasyonundaki etkileri incelenmiştir. İncelemede, fırçasız motor hızını ayarlayan elektronik hız kontrol ünitesi sinyali, fırçasız motorun dakikadaki dönüş sayısı, pervanenin çapı ve hatvesi giriş parametreleri olarak; gerekli itki kuvveti, uçuş süresi ve motor verimliliği çıkış parametreleri olarak seçilmiştir. GAO algoritması ilk önce, deneysel olarak elde edilen veriler kullanılarak, optimum YSA model parametrelerinin belirlenmesinde kullanılmıştır. Daha sonra, optimum olarak belirlenen YSA yapısı amaç fonksiyonunu gerçekleştirmek için kullanılmış ve GAO algoritmasına entegre edilerek maksimum çıkş̧ parametrelerini veren optimum giriş parametrelerinin elde edilmesi sağlanmıştır.

Fırçasız motor performansının ve uçuş süresinin eş zamanlı ve eşit önemde dikkate alınmasında geniş bir kombinasyonun değerlendirilmesi gerekmektedir. Yapılan çalışmanın sonuçları, GAO algoritması tabanlı YSA modelinin, farklı olasılıkların, daha az maliyet ve zaman kaybıyla değerlendirilmesinde etkin bir şekilde kullanılabileceğini göstermiştir. Böylece, farklı özelliklerdeki İHA problemlerinin çözümünde, önerilen yöntemin, mevcut yöntemlere alternatif olacağı söylenebilir.

\section{Kaynaklar}

[1] Austin, R. (2011). Unmanned aircraft systems: UAVS design, development and deployment (Vol. 54). John Wiley \& Sons.

[2] Daniel, P. R. (1992). Aircraft design: a conceptual approach. Published by American Institute of Aeronautics and Astronautics Inc.

[3] Oktay, T., Arik, S., Turkmen, I., Uzun, M., \& Celik, H. (2018). Neural network based redesign of morphing UAV for simultaneous improvement of roll stability and maximum lift/drag ratio. Aircraft Engineering and Aerospace Technology, 90(8), 1203-1212.

[4] Arik, S., Turkmen, I., \& Oktay, T. (2018). Redesign of morphing UAV for simultaneous improvement of directional stability and maximum lift/drag ratio. Advances in Electrical and Computer Engineering, 18(4), 57-62.

[5] Konar, M. (2018). Determination of UAVs thrust system parameters by artificial bee colony algorithm. ICENS 4th International Conference on Engineering and Natural Science, Kiev, Ukraine.

[6] Traub, L. W. (2011). Range and endurance estimates for battery-powered aircraft. Journal of Aircraft, 48(2), 703-707.

[7] Gur, O., \& Rosen, A. (2009). Optimizing electric propulsion systems for unmanned aerial vehicles. Journal of Aircraft, 46(4), 1340-1353.

[8] Lawrence, D., \& Mohseni, K. (2005). Efficiency analysis for long duration electric MAVs. In Infotech@ Aerospace Conferences, Arlington, Virginia.

[9] Avanzini, G., \& Giulietti, F. (2013). Maximum range for battery-powered aircraft. Journal of Aircraft, 50(1), $304-307$.

[10]Elkhedim, B., Benard, E., Bronz, M., Gavrilovic, N., \& Bonnin, V. (2016). Optimal design of long endurance mini UAVs for atmospheric measurement. Applied Aerodynamics Conference, Bristol, United Kingdom.

[11] Hepperle, M. (2012). Electric flight-potential and limitations. Energy Efficient Technologies and Concepts of Operation, Lisbon, Portugal.

[12] Chang, T., \& Yu, H. (2015). Improving electric powered UAVs' endurance by incorporating battery dumping concept. Procedia Engineering, 99, 168-179. 
[13] Civicioglu, P. (2013). Backtracking search optimization algorithm for numerical optimization problems. Applied Mathematics and Computation, 219(15), 8121-8144.

[14] Civicioglu, P., \& Besdok, E. (2018). A+ Evolutionary search algorithm and QR decomposition based rotation invariant crossover operator. Expert Systems with Applications, 103, 49-62.

[15] Haykin, S., Neural networks-a comprehensive foundation, 2nd ed., Prentice Hall, 1999.

[16] Bağiş A., \& Konar M. (2010). Uçuş kontrol sistemi yakıt parametresinin yapay sinir ağları kullanılarak belirlenmesi. Akıllı Sistemlerde Yenilikler ve Uygulamaları Sempozyumu (ASYU'2010), Kayseri, Türkiye, 104-108.

[17]Konar, M., \& Bagiş, A. (2016). Simultaneous computation of the speed and fuel parameters of flight control system by using Anfis and artificial neural networks. 24th Signal Processing and Communication Application Conference (SIU 2016), 1389-1392.

[18] Bagis, A., \& Konar, M. (2016). Comparison of Sugeno and Mamdani fuzzy models optimized by artificial bee colony algorithm for nonlinear system modelling. Transactions of the Institute of Measurement and Control, 38(5), 579-592.

[19] Konar, M., \& Bagis, A. (2016). Performance comparison of particle swarm optimization, differential evolution and artificial bee colony algorithms for fuzzy modelling of nonlinear systems. Elektronika ir Elektrotechnika, 22(5), 8-13. 